\title{
Metode Pumping Test sebagai Kontrol Untuk Pengambilan Airtanah Secara Berlebihan
}

\author{
Harjito \\ Laboratorium Hidrologi dan Kualitas Air Fakultas Geografi UGM \\ Email : jitoo_2007@yahoo.co.id
}

\begin{abstract}
Abstrak
Tujuan studi ini adalah untuk mengetahui perkiraan potensi debit airtanah, debit optimum yang tersedia dan mengetahui debit airtanah yang telah diambil atau dieksploitasi pada salah satu pelaku usaha di kota Yogyakarta. Metode analisis yang digunakan adalah metode Pumping Test Theis Recovery, dengan uji sumur dan uji akuifer. Berdasarkan uji sumur (well test) dan uji akuifer (aquifer test) berdasarkan hasil rekonstruksi litologi, maka potensi airtanah didaerah studi (Qp) adalah 69,65 liter/detik. Debit optimum (Qopt.) yang tersedia 5,8 liter/detik, sedangkan debit pengambilan atau debit operasi sumur yang terjadi berdasarkan data daerah studi (Qop) adalah 7,3108 liter/detik sehingga debit pemompaan tidak melebihi debit potensi airtanah. Pengaruh pengambilan airtanah yang berlebihan adalah penurunan permukaan airtanah yang berakibat buruk terhadap kondisi ketersediaan air. Langkah-langkah pengelolaan airtanah dan konservasinya antara lain menjaga kelestarian lingkungan dan mengendalikan eksplorasi airtanah serta memperhatikan pengaruh pemompaan dan penurunan muka airtanah, dengan menentukan jarak minimum (2R) antar titik sumur dan debit pemompaan tidak melebihi debit optimum yang tersedia. Dengan langkah-langkah pengelolaan seperti tersebut di atas diharapkan perubahan atau penurunan permukaan airtanah akibat pemompaan tidak melebihi titik batas yang seharusnya.
\end{abstract}

Kata Kunci : Debit optimum, debit pengambilan, potensi airtanah, pumping test

\section{PENDAHULUAN}

\section{Latar Belakang}

Air adalah materi atau unsur yang sangat penting bagi semua kehidupan di muka bumi ini. Manusia dan semua makhluk lainnya membutuhkan air (Kodoatie dan Sjarief, 2010). Salah satu dampak yang pasti terjadi akibat tidak terjaganya kawasan konservasi adalah bahaya habisnya cadangan airtanah dan jumlah debit limpasan permukaan pada saat musim hujan semakin besar dan memberikan pengaruh cukup dominan terhadap bahaya banjir seperti di daerah Jakarta dan kotakota lainnya. Beberapa hal yang menjadi masalah adalah pengambilan airtanah yang tidak terkontrol dan langkah konservasi yang kurang diperhatikan menyebabkan ketersediaan airtanah jangka panjang semakin menipis, lahan terbuka hijau yang semakin berkurang memperburuk kondisi lingkungan dan resapan air sehingga ketika musim kemarau datang terjadi kekeringan dan saat musim hujan tiba terjadi genangan dimana-mana serta kurangnya penanganan konservasi dari instansi terkait maupun masyarakat lingkungan sekitar. 
Metode pengukuran debit air untuk sumber air bergerak (tampak alirannya) biasanya mengunakan metode pengukuran benda apung dan juga metode pengukuran dengan menggunakan alat ukur. Hal ini disebabkan karena adanya factor kecocokan dan kemudahan dalam hal pelaksanaanya. Berbeda halnya dengan sumber air diam, pengukuran debit sumber air diam paling cocok adalah dengan menggunakan pumping test.

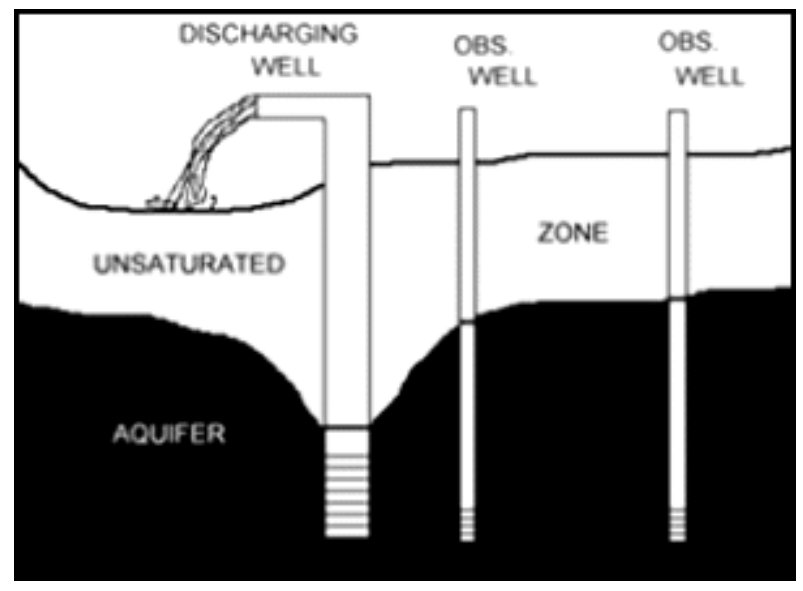

Gambar 1. Penampang akuifer (Goldscheider, 2010)

Pumping test merupakan metode pengukuran debit air yang beride dari pengamatan kontinuitas sumber air dan ketersedian air dari sumber itu sendiri. Hal yang menjadi inti dari pumping test ini adalah perbandingan antara penurunan muka air pada saat pumping terhadap kenaikan muka air pada saat recovery dala tenggat waktu yang sama. Beberapa kemungkinan dari keadaan pengukuran debit dengan pumping test antara lain:

1. Jika perbandingan dari dua keadaan ini (laju penurunan muka air pada saat pumping terhadap laju kenaikan muka air ketika recovery) adalah 1 maka debit sumber $=$ debit air yang dikeluarkan pompa (output pompa).

2. Jika laju penurunan muka air pada saat pumping lebih besar terhadap laju kenaikan muka air ketika recovery, berarti debit sumber lebih kecil daripada debit pompa (output).

3. Jika laju penurunan muka air pada saat pumping lebih kecil terhadap laju kenaikan muka air ketika recovery, berarti debit sumber lebih besar daripada debit pompa (output).

Untuk mendapatkan nilai debit sesungguhnya dari sumber dapat diketahui dengan mengalikan luas area sumber dengan tinggi kenaikan muka air air rata-rata pada saat recovery. 
Di kota Yogyakarta terdapat beberapa industri baik yang berskala menengah maupun kecil. Dalam rangka perlindungan terhadap sumberdaya airtanah sesuai amanat undang-undang maka pemerintah mewajibkan pelaku usaha untuk mengajukan perizinan mengenai pemanfaatan airtanah. Oleh sebab itu pelaku usaha ini harus melakukan pumping test sebagai salah satu dokumen untuk mengajukan pemanfaatan airtanah, sehingga akan diketahui debit optimum yang dapat diambil dalam rangka alat kontrol untuk pengambilan airtanah secara berlebihan.

\section{Maksud dan Tujuan}

Studi ini dimaksudkan untuk mendapatkan gambaran yang lebih mendalam tentang potensi airtanah disekitar sumur produksi pelaku usaha.

Adapun tujuan dari studi ini adalah sebagai berikut:

a. Mengetahui debit airtanah yang telah diproduksi atau dieksploitasi berdasarkan data sumur bor.

b. Mengetahui debit optimum dan maksimum yang tersedia.

\section{METODOLOGI}

Metode yang digunakan dalam uji pompa kali ini adalah Theis Recovery. Theis (1935) mengembangkan metode ini untuk mendapatkan nilai transmisivitas (T). Metode ini mudah dilakukan karena tidak membutuhkan sumur pantau ketika uji pompa. Sumur yang dipompa sekaligus dijadikan sumur pantau.

\section{Alat dan Bahan Penelitian}

\section{HOBO-Ware Automatic Water Level Logger}

Alat ini merupakan pencatat tinggi muka air otomatis yang mencatat fluktuasi TMA berdasarkan perubahan tekanan. Dua buah logger digunakan dalam penelitian ini yang dipasang dalam sumur dan udara. Logger yang dipasang di udara berfungsi untuk kalibrasi tekanan barometrik sehingga pencatatan tekanan dalam air akan lebih presisi.

2. Software HOBO dan seperangkat komputer

Kedua perangkat ini digunakan untuk mengatur interval pencatatan dan membaca hasil perekaman logger. Data perekaman yang tercatat nantinya akan ditampilkan dalam bentuk tabular dan grafik. Kedua hasil tersebut akan menunjukkan perubahan tinggi muka air tanah ketika sumur dipompa. 


\section{Sumur Pantau}

Sumur adalah sumur yang diukur fluktuasi muka air tanahnya ketika sumur produksi dipompa.

4. Sumur Observasi

Sumur yang digunakan adalah sumur yang berada di sekitar area pabrik SGM. Tinggi muka air sumur diamati sebelum pompa pada sumur produksi dinyalakan dan ketika proses pemompaan sedang berjalan. Pengukuran ini bertujuan untuk mengetahui apakah pemompaan sumur produksi berpengaruh terhadap tinggi muka air pada sumur penduduk di sekitar pabrik ketika pompa beroperasi.

\section{Pita Ukur}

Pita ukur digunakan untuk mengukur kedalaman muka air atau sumur secara manual. Pita ukur juga digunakan untuk mengukur jarak antara sumur produksi dengan sumur pantau.

6. GPS Receiver

GPS receiver atau Global Positioning System Receiver adalah alat yang digunakan untuk mengetahui posisi absolut suatu objek. Alat ini menerima sinyal dari beberapa satelit yang berada dalam jangkauannya untuk menentukan posisi absolut. Alat ini digunakan untuk pencatatan koordinat sumur yang digunakan saat pumping test.

\section{Teknik Pengukuran}

Tahap-tahap yang dilakukan dalam proses pumping test adalah sebagai berikut:

a. Tentukan Sumur pantau dan sumur observasi yang akan diukur tinggi muka airnya ketika sumur uji dipompa;

b. Catat lokasi absolut masing-masing sumur tersebut;

c. Pastikan sumur produksi tidak sedang dipompa dalam jangka waktu dekat sebelum pemompaan minimal 24 jam, agar muka airtanah berada pada kondisi normal;

d. Ukur tinggi muka airtanah sumur pantau dan sumur observasi sebelum sumur uji dipompa;

e. Siapkan Automatic Water Level Logger dan luncurkan dengan mengatur waktu perekaman tertentu. Semakin dekat interval perekaman maka data yang dihasilkan akan semakin bagus. Untuk pemompaan selama 1 jam minimal interval pegukuran tinggi muka air selama 5 menit. 
f. Pasang satu logger yang sudah diluncurkan ke dalam sumur pantau dan satu lagi diletakkan di tempat terbuka (udara) dengan lokasi yang tidak jauh dari sumur pantau. Fungsi logger ini sebagai kalibrasi tekanan udara;

g. Catat waktu ketika pompa mulai dihidupkan, minimal pompa dinyalakan selama 100 menit atau lebih untuk mendapatkan satu siklus log penuh;

h. Catat tinggi muka air pada sumur observasi ketika pompa sudah menyala selama kurang lebih satu jam;

i. Matikan pompa setelah waktu pemompaan yang ditentukan selesai;

j. Biarkan logger tetap merekam tinggi muka airtanah sumur pantau ketika pompa sudah dimatikan, tunggu sekitar 1 jam agar akuifer mengisi kembali;

k. Ambil logger dan unduh data perekaman;

1. Analisis data hasil perekaman logger.

\section{Cara Analisis Data Pumping Test}

a. Uji sumur (well test) terkait dengan trend penurunan muka airtanah, kapasitas jenis umur, kondisi sumur dan kelas sumur, debit dan penurunan muka airtanah optimum.

b. Perhitungan jari-jari pengaruh pemompaan.

c. Uji akuifer (Aquifer test) terkait dengan nilai-nilai Trasmisivitas (T), Storativity (Sr), Permeabilitas (K), penurunan muka airtanah akibat pemompaan (cone depression) berdasarkan metode yang sesuai karakteristik data.

d. Implementasi bor log sumur terhadap litologi airtanah daerah studi.

e. Implementasi jari-jari pengaruh pemompaanterhadap topographi daerah studi.

f. Langkah-langkah mendasar yang harus dilakukan sebagai bagian dari upaya konservasi airtanah tersebut. 


\section{HASIL DAN PEMBAHASAN}

a. Menghitung debit airtanah

Debit airtanah merupakan jumlah air yang mengalir dari suatu penampang dalam satuan waktu $\left(\mathrm{m}^{3} /\right.$ detik). Laju airtanah dipengaruhi oleh kondisi litologi. Berdasarkan rekonstruksi litologi diketahui bahwa lapisan akuifer berada di daerah pengendapan alluvium dengan material pasiran (Tabel 2). Material ini mempunyai sifat menahan air dan meloloskan airtanah dengan relative cepat. Menurut Fetter (1994) material pasir mempunyai porositas yang baik yaitu 10\%-20\%. Berdasarkan litologi tersebut sifat fluida dapat dilolosakan dengan cepat karena rongga antar ruang butir yang besar. Sifat tersebut bila dikorelasikan nilai konduktivitas (Tabel 1) dengan material pasir mempunyai nilai rentang pasir sedang $12 \mathrm{~m} /$ hari hingga pasir kasar $45 \mathrm{~m} /$ hari. Nilai Konduktivitas hidrolik disekitar pabrik rata-rata adalah 23.53 m/hari (PT. Sari Husada, 2008).

Tabel 1. Litologi di Sidobali, Mujamuju, Umbulharjo, Yogyakarta

\begin{tabular}{|c|c|c|c|c|}
\hline $\begin{array}{c}\text { Resistivity }(\Omega \\
\text { meter })\end{array}$ & $\begin{array}{l}\text { Tebal } \\
\text { lapisan } \\
\text { (meter) }\end{array}$ & Profi & & Material/Keterangan \\
\hline 2,33 & 0,221 & \multirow{3}{*}{\multicolumn{2}{|c|}{ 0,221 }} & $\begin{array}{l}\text { Lapisan tanah atas } \\
\text { mengandung lengas tanah }\end{array}$ \\
\hline 45,9 & 72,1 & & & $\begin{array}{l}\text { Akuifer jenuh airtanah } \\
\text { material pasir lempung, } \\
\text { aluvium }\end{array}$ \\
\hline 1963 & $>100$ & & & $\begin{array}{l}\text { Akuifer jenuh airtanah } \\
\text { material tuff serpih, abu } \\
\text { endapan merapi muda }\end{array}$ \\
\hline
\end{tabular}

Sumber : PT. Sari Husada (2008)

Kondisi aliran airtanah mengikuti kondisi topografi di permukaan. Arah aliran airtah (flownet) disekitar pabrik PT. Sari Husada mengarah ke Timur dan Tenggara (Gambar 4). Arah aliran tersebut masuk kedalam sungai Gajahwong. Arah aliran airtanah di sisi Timur pabrik PT. Sari Husada aliran airtanahnya mengalir ke Timur menuju sungai Gajahwong. Sedangkan kondisi Selatan pabrik PT. Sari Husada aliran airtanahnya mengalir ke Tenggara menuju sungai Gajahwong. Kondisi aliran airtanah dipengaruhi oleh topografi dipermukaan yang rendah di daerah sungai Gajahwong. Kemiringan rata-rata kontur permukaan di sekitar pabrik PT. Sari Husada $13^{0}$, sedangkan kemiringan kontur airtanah adalah $15^{\circ}$. 


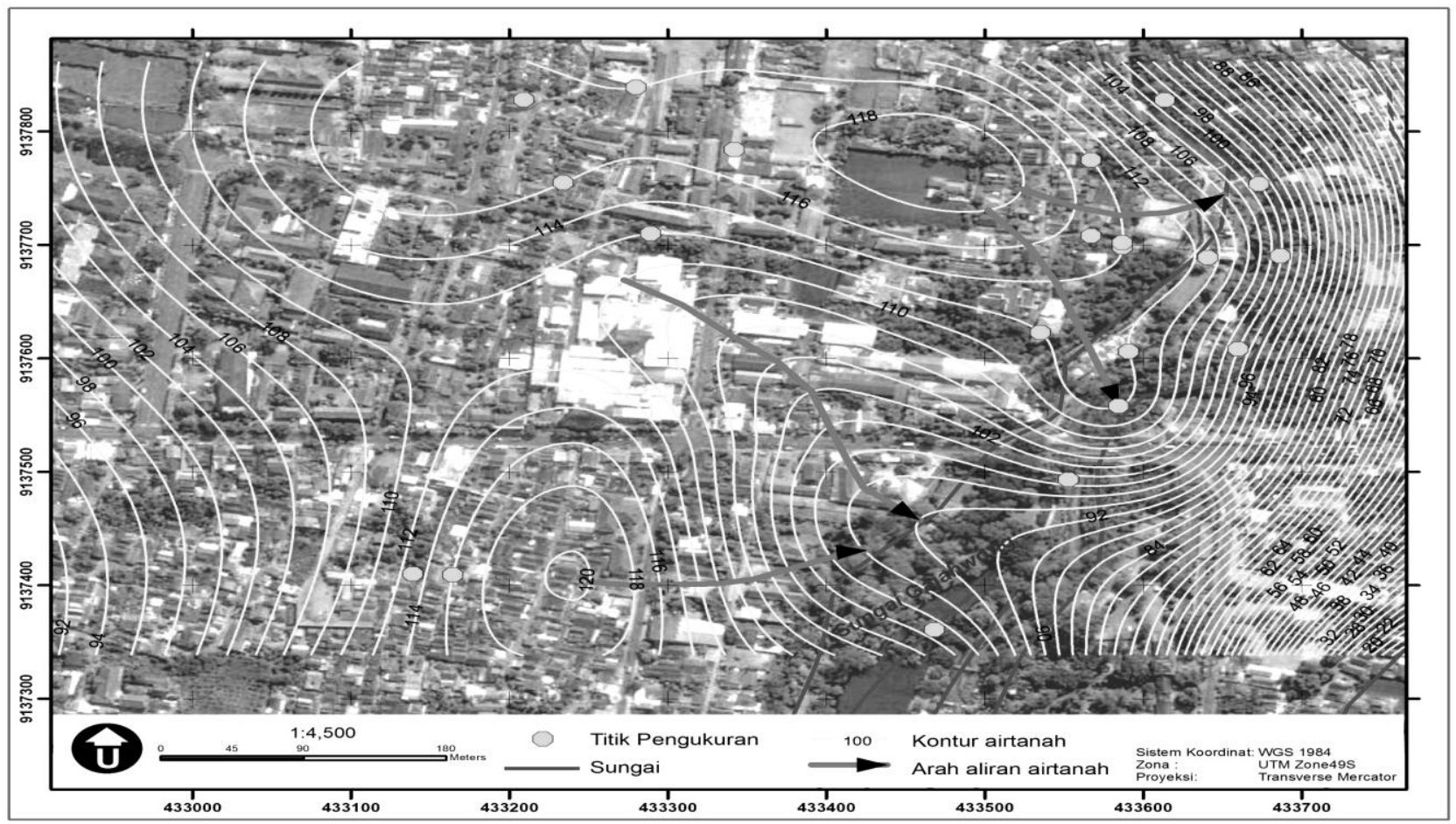

Gambar 2. Kontur airtanah di sekitar Pabrik PT. Sari Husada

Ketebalan akuifer dangkal berdasarkan rekonstruksi litologi (Tabel 2) di sekitar pabrik PT. Sari Husada adalah 8-15 meter. Kondisi ini menerus hingga pertemuan dengan Sungai Gajahwong, Kondisi dasar sungai terisi oleh aliran airtanah sehingga menjadi baseflow di sungai tersebut. Akuifer berada dekat dengan permukaan, sehingga saat aliran bersinggungan dengan aliran sungai, maka akuifer tersebut ikut mengisi aliran sungai tersebut (Todd, 1980).Berdasarkan kondisi tersebut debit airtanah dengan metode Hukum Darcy dengan konsep bahwa suatu aliran mengalir pada suatu penampang yang seragam dengan gaya gravitasi yang diperoleh dari kemiringan kontur airtanah. Perhitungan Debit dengan Hukum Darcy:

$\mathbf{Q}=\mathbf{K} . \mathbf{I} \cdot \mathbf{A}$

Keterangan :

$\mathrm{K}=$ hydraulic conductivity $(\mathrm{m} / \mathrm{hari})$

$\mathrm{I}=$ hydraulic gradient $(\mathrm{dh} / \mathrm{dL})$

$\mathrm{A}=$ luas penampang akuifer

Diketahui : $\mathrm{K}=23.53 \mathrm{~m} / \mathrm{hari}$

$I=(3.1) /(20 \times 10 / 20)$

$\mathrm{I}=0.31$

$A=15 \mathrm{~m} \times 55 \mathrm{~m}$

$A=825 \mathrm{~m}^{2}$ 
Sehingga :

$$
\begin{aligned}
& \mathrm{Q}=\text { K.I.A } \\
& \mathrm{Q}=23.53 \times 0.31 \times 825 \\
& Q=6.017,798 \mathrm{~m}^{3} / \text { hari }
\end{aligned}
$$

Berdasarkan perhitungan dengan konduktivitas hidrolik/permeabilitas $23.53 \mathrm{~m} / \mathrm{hari}$ diketahui potensi debit airtanah (Q) di sekitar pabrik PT. Sari Husada adalah $6.017,798 \mathrm{~m}^{3} / \mathrm{hari}=69.65 \mathrm{lt} / \mathrm{dt}$.

b. Mengetahui debit optimum dan maksimum yang tersedia.

Sesuai dengan latar belakang studi tentang potensi airtanah dan debit optimum sumur yang seharusnya dijadikan acuan dasar dalam pengambilan/eksploitasi airtanah tersebut adalah seperti analisis berikut ini. Tujuan utama dilakukannya uji pompa adalah untuk mengetahui karakter kemampuan akuifer seperti konduktivitas hidrolik dan transmisivitas. Lebih spesifik, dalam hal ini uji pompa dilakukan untuk mengetahui kemampuan residual drawdown akuifer untuk mengisi kembali setelah sumur dipompa. Uji pompa juga bertujuan untuk mengetahui pengaruh pemompaan sumur produksi terhadap kondisi muka airtanah sumur yang ada di sekitarnya. Metode yang digunakan dalam uji pompa kali ini adalah Theis Recovery. Theis (1935) mengembangkan metode ini untuk mendapatkan nilai transmisivitas (T). Metode ini mudah dilakukan karena tidak membutuhkan sumur pantau ketika uji pompa. Sumur yang dipompa sekaligus dijadikan sumur pantau. Rumus yang digunakan untuk menghitung nilai transmisivitas adalah sebagai berikut :

$\mathrm{T}=\frac{2,3 \times Q}{4 x \pi x \Delta S}$

$\mathrm{T}=$ Transmisivitas $\left(\mathrm{m}^{2} /\right.$ hari $)$

$\mathrm{Q}=$ Debit pemompaan

$\Delta \mathrm{S}^{\prime}=$ Selisih kenaikan residual drawdown 


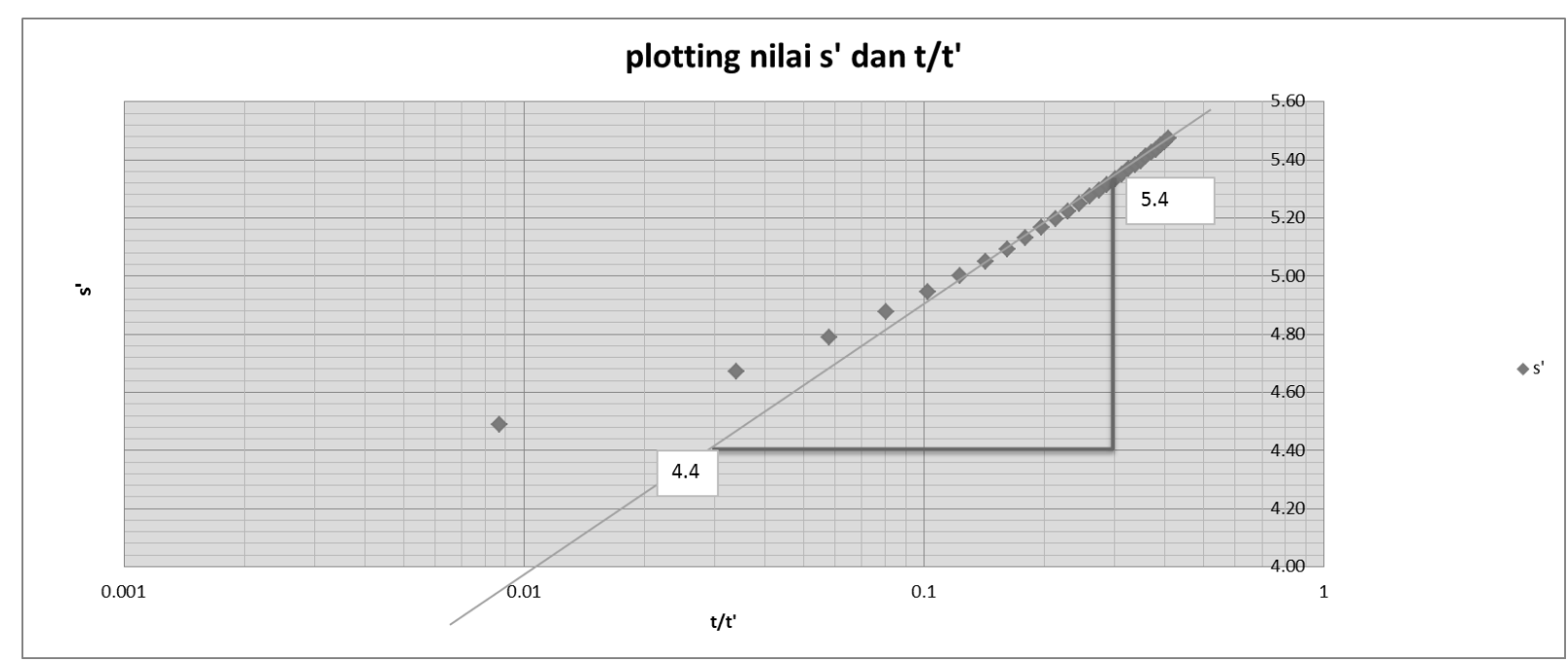

Gambar 3. Grafik Penentuan Nilai Delta s'

Perhitungan koefisien permeabilitas dari long period :

\begin{tabular}{|c|r|c|}
\hline$\Delta$ & & \\
$s^{\prime}$ & $Q($ liter/detik) & b \\
\hline 1.0 & 10.1 & 24 \\
\hline
\end{tabular}

$$
\begin{aligned}
\mathrm{T} & =\frac{2,3 \times Q}{4 \times \pi \times \Delta S} \\
T & =\frac{2,3 \times 475.2}{4 \times 3,14 \times 1} \\
& =109,96 / 12.56 \\
& =87,0191 \mathrm{~m}^{2} / \text { hari }
\end{aligned}
$$

$\mathbf{K}=\frac{T}{b}=\frac{87,0191 \mathrm{~m} 2 / \mathrm{hari}}{40 \mathrm{~m}}=2.175477707 \mathrm{~m} / \mathrm{hari}=0.000025 \mathrm{~m} / \mathrm{detik}$

Perhitungan debit maksimum :

$$
\begin{array}{ll}
\text { Q max }=2 \times \pi \times \text { re } \times \text { b } \times \frac{\sqrt{\mathrm{K}}}{15} & \text { re }=\frac{r \text { lubang }+r \text { saringan }}{2} \\
=2 \times 3,14 \times 0,145 \times 40 \times \frac{\sqrt{0.000025}}{15} & =8 ”+3 " / 2 \\
=0.007310853 \mathrm{~m}^{3} / \text { detik } & =5,5 “ \\
=\mathbf{7 . 3 1 0 8 5 3 4 1 1 l i t e r / d e t i k} & =0,145 \mathrm{~m}
\end{array}
$$

\section{Q optimum : 5,8 liter/detik}




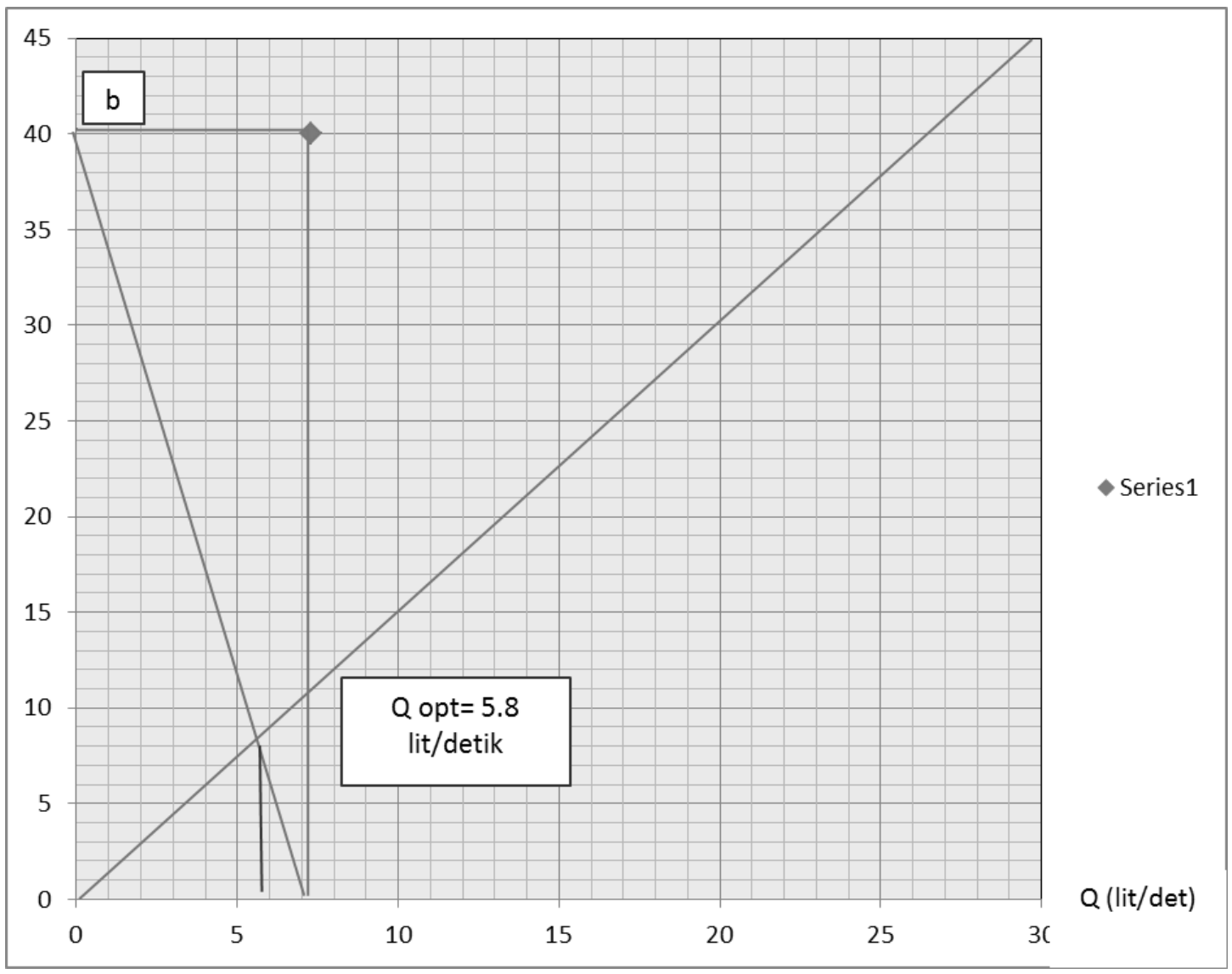

Gambar 4. Perhitungan debit maksimum dari pumping test sumur produksi

Berdasarkan hasil pemompaan didapatkan nilai transmisivitas sebesar $159.799 \mathrm{~m}^{2} /$ hari. Nilai ini tergolong besar, semakin besar nilai $\mathrm{T}$ maka cone of depression cenderung lebih landai. Debit maksimum yang dapat dipompa pada sumur produksi adalah sebesar 7.31 liter/detik. Dengan debit optimum pemompaan sebesar 5.8 liter/detik.

\section{KESIMPULAN DAN SARAN}

\section{Kesimpulan}

Berdasarkan hasil uji pemompaan di sumur produksi diperoleh debit pemompaan maksimum sebesar 7.31 liter/detik dan debit optimum sebesar 5.8 liter/detik. Debit airtanah berdasarkan hasil perhitungan diperoleh 69.65 lt/dt sehingga debit pemompaan sumur produksi tersebut tidak berpengaruh terhadap kondisi sumur penduduk yang ada di sekitar . 


\section{Saran}

Debit pengambilan atau debit operasi harus diturunkan hingga lebih kecil atau sama dengan debit optimum sesuai hasil perhitungan agar konservasi airtanahnya tetap terjaga. Untuk menyesuaikan syarat dan langkah analisis sesuai teori yang ada, instansi terkait dalam pelaksanaan pengeboran airtanah dan uji pumping test harus bertahap secara teratur dari debit terkecil hingga terbesar hingga diperoleh penurunan muka air yang relatif stabil. Setiap pekerjaan sumur bor untuk airtanah dalam harus dibuat pula sumur pantau minimal 1 (satu) buah sebagai kontrol pengaruh penurunan muka airtanah sekitarnya. Instansi terkait yang memberikan ijin pengeboran harus membuat standar operasional prosedur (SOP) yang bertujuan untuk kelestarian dan kelangsungan ketersediaan airtanah dengan syarat-syarat yang wajib dipenuhi oleh setiap pelaku ekplorasi airtanah. Langkahlangkah yang harus diambil terkait konservasi airtanah adalah menjaga kelestarian lingkungan dan mengendalikan eksplorasi airtanah dengan tidak berlebihan serta memperhatikan pengaruh pemompaan dan penurunan muka airtanah, salah satunya adalah menentukan jarak minimum antar titik sumur dalam. Jarak minimum ditentukan oleh debit dan jari-jari pengaruh pemompaan sumur terdekat yang ada dengan ketentuan bahwa debit yang direncanakan tidak melebihi debit sumur terdekat yang sudah beroperasi, sehingga pada lokasi studi masih memungkinkan penambahan sumur akan tetapi kaidah jarak harus diperhatikan. Langkah-langkah pengelolaan airtanah dan konservasinya antara lain menjaga kelestarian lingkungan dan mengendalikan eksplorasi airtanah serta memperhatikan pengaruh pemompaan dan penurunan muka airtanah, dengan menentukan jarak minimum (2R) antar titik sumur dan debit pemompaan tidak melebihi debit optimum yang tersedia. Dengan langkah-langkah pengelolaan seperti tersebut di atas diharapkan perubahan atau penurunan permukaan airtanah akibat pemompaan tidak melebihi titik batas yang seharusnya. 


\section{DAFTAR PUSTAKA}

Acworth, R.I., 2001a, Electrical Methods in Groundwater Studies, Short Course Note, School of Civil and Environmental Engineering, University of New South Wales, Sydney, Australia.

Bonacci, O., 1990, Regionalization in Karst Regions, Proceedings of the Ljubljana Symposium. April 1990, IAHS Publ. no. 191, 1990.

Ford, D. and Williams, P., 1992, Karst Geomorphology and Hydrology, Chapman and Hall, London

Goldscheider, Nico and Drew, 2010, Karst and Alpine Hydrogeology, Karlsruhe Institute of Technology, Institute of Applied Geosciences.

Jankowski, J., 2001, Hydrogeochemistry, Short Course Note, School of Geology, University Of New South Wales, Sydney, Australia

Linsley, R.K., Kohler, M.A., Paulhus, J.L., 1975, Hydrology for Engineers, 2nd. Ed, Mc Graw Hill Kogakusha Ltd. Tokyo, Japan

MacDonalds and Partners, 1983, Greater Yogyakarta - Groundwater Resources Study. Vol 1: Main Report. Yogyakarta, Directorate General of Water Resources Development Project (P2AT)

Todd, D.K., 1980, Groundwater Hydrology. 2nd Ed. John Wiley \& Sons

White, W.B., 1988, Geomorphology and Hydrology of Karst Terrain. Oxford University Press, New York 